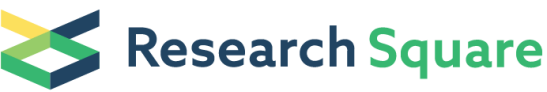 \\ Preprints are preliminary reports that have not undergone peer review. \\ They should not be considered conclusive, used to inform clinical practice, or referenced by the media as validated information.
}

\section{Analysis of Peripheral Inflammatory T Cell Subsets and Their Effector Function in Patients With Birdshot Retinochoroiditis}

\section{Janine Trombke}

Regenerative Immunology and Aging, BIH Center for Regenerative Therapies, Charité Universitätsmedizin Berlin, Berlin, Germany

\section{Lucie Loyal}

Regenerative Immunology and Aging, BIH Center for Regenerative Therapies, Charité Universitätsmedizin Berlin, Berlin, Germany

\section{Braun Julian}

Regenerative Immunology and Aging, BIH Center for Regenerative Therapies, Charité Universitätsmedizin Berlin, Berlin, Germany

\section{Pleyer Uwe}

Charité - Universitätsmedizin Berlin, corporate member of Freie Universität Berlin, Humboldt Universität zu Berlin, and Berlin Institute of Health, Berlin, Germany

\section{Thiel Andreas}

Regenerative Immunology and Aging, BIH Center for Regenerative Therapies, Charité Universitätsmedizin Berlin, Berlin, Germany

\section{Pohlmann Dominika ( $\nabla$ dominika.pohlmann@charite.de )}

Charité - Universitätsmedizin Berlin, corporate member of Freie Universität Berlin, Humboldt Universität zu Berlin, and Berlin Institute of Health, Berlin, Germany

\section{Research Article}

Keywords: Birdshot Retinochroidititis, memory T cells, inflammatory T cell subsets, T cell effector function, CD8+ TEMRA, chemokine receptors

Posted Date: December 28th, 2020

DOI: https://doi.org/10.21203/rs.3.rs-127465/v1

License: (c) (i) This work is licensed under a Creative Commons Attribution 4.0 International License. Read Full License

Version of Record: A version of this preprint was published at Scientific Reports on April 21st, 2021. See the published version at https://doi.org/10.1038/s41598-021-88013-0. 


\section{Abstract}

Purpose: Birdshot Retinochoroiditis (BSRC) is a progressive non-infectious intraocular inflammation that affects choroid and retina. Inflammatory processes have adverse effects on vision by affecting photoreceptor-bearing cells that do not regenerate.

Methods: This study aimed at characterizing inflammatory $\mathrm{CD} 4^{+}$and $\mathrm{CD} 8^{+} \mathrm{T}$ cell subsets in the peripheral blood of BSRCs. Furthermore, we correlated phenotypical and functional immunological analyses with clinical data.

Results: We observed a slight increase of terminally differentiated effector memory $C D 8^{+} T$ cells expressing CD45RA $\left(T_{E M R A}\right)$ in blood of inactive, compared to active BSRCs. Moreover, we identified a trend for a decreased population of $\mathrm{T}_{\mathrm{H}} 2$ cells and increased $\mathrm{T}_{\mathrm{H}} 1$ frequencies in active BSRCs, a typical sign of ongoing autoimmune processes. Functional assays demonstrated severe and overall impairment of effector function of both, CD $4^{+}$and $\operatorname{CD} 8^{+}$ inflammatory $\mathrm{T}$ cells, which might reflect $\mathrm{T}$ cell exhaustion.

Conclusion: Although the eye is the main site of inflammation in BSRC, we observed altered T cell subset compositions in the peripheral blood, dependent on the disease status. Our results indicate that T cells may play a major role in BSRC pathology, although our cohort size is too limited for definitve conclusions. Future studies with larger and well-defined cohorts of BSRCs have to be performed.

\section{Introduction}

Birdshot Retinochoroiditis (BSRC) is a rare form of non-infectious posterior uveitis, in which recurrent inflammatory episodes affect retina and stromal choroid. ${ }^{1}$ Patients with BSRC present with mainly bilateral typical hypopigmented choroidal 'birdshot lesions' around the fundus, which are suspected to be associated with the formation of lymphocytic aggregations (foci) in the choroid, optic nerve, and along the retinal vasculature. ${ }^{2}$ Clinically, the patients suffer from floater, blurred vision, and sensitivity to light (photopsia). Over the many years of the course of the disease, the patients develop visual impairment including decreased visual acuity, peripheral vision, blindness at night (nyctalopsia) and blindness for colors (dyschromatopsia). Although this rare disease is clinically well characterized, the etiology and the pathophysiology of BSRC remain uncertain.

Evidences from human and mouse studies suggest that both, the innate and adaptive immune system contribute to the manifestation of non-infectious posterior uveitis, like BSRC. ${ }^{3-5}$ Due to the strong association of BSRC to the human lymphocyte antigen (HLA) class I A*29.2 (relative risk of 224.35), a particular role in disease pathology can be attributed to T cells. ${ }^{6}$ Indeed, analyses of vitreous fluids revealed the presence of retina and choroid-reactive intraocular $\mathrm{CD}^{+}$and $\mathrm{CD} 8^{+} \mathrm{T}$ cells in disease-active BSRC eyes proving their presence in an ongoing autoinflammatory response. ${ }^{8}$ Kuiper and colleagues further strengthened this body of evidence by the discovery of certain polymorphisms in the endoplasmic reticulum aminopeptidase (ERAP) gene of BSRC patients leading to imbalanced ERAP 1 and 2 function, thus influencing peptide-presentation of HLA-A ${ }^{*} 29$ to T cells. ${ }^{7}$ ERAP enzymes are necessary to process peptides for loading onto major histocompatibility complex I (MHC-I) on nucleated cells prior to surface transport. MHC-I presented peptides in turn are then recognized by CD8 ${ }^{+} \mathrm{T}$ cells that can initiate an immune response, thus generating immunological memory. Further supportive evidences were presented in studies showing improvement of ocular inflammation and visual acuity by corticosteroid-sparing immunomodulatory therapies. ${ }^{8-16}$

It was shown that the $C D 4^{+} T$ helper subset $T_{H} 17$ might be important to sustain chronic inflammation in various autoimmune diseases, such as psoriasis, inflammatory bowel disease, rheumatoid arthritis, and multiple sclerosis. ${ }^{17-}$ 
20 In line with these studies, T cells of BSRC patients produced IL-17 in response to human and choroid lysate and IL -17 secreting $C D 4^{+}$and $C D 8^{+}$T cells have been demonstrated to be enriched in the periphery of BSRC patients. ${ }^{21-23}$ In addition, increased IL-17 and pro-inflammatory cytokines were presented in aqueous humor and serum of BSRC patients, suggesting IL-17 pathway activity. ${ }^{4,24}$ However, most of these results were only noticeable in disease-active, treatment-naïve BSRC patients only. This may hint at a role rather in the establishment of auto-inflammatory episodes in BSRC pathology and excludes IL-17 producing T cells as marker for BSRC disease activity. Other cellular parameters have to be identified as markers for disease activity.

Several studies utilized distinct chemokine receptor expression patters to describe multiple subsets of CD $4^{+}$and $C D 8^{+}$ T cells. ${ }^{25,26}$ Chemotactic receptors might give additional or more precise information about the abundance and origin of certain peripheral T cell compartments in BSRC disease. To gain insights in the T cell biology of BSRC, we conducted a study enrolling 11 BSRC patients that underwent clinical examination using multimodal imaging techniques and disease staging. ${ }^{27}$ In parallel, we examined the abundance of certain memory T cell subsets. To assess relevant $\mathrm{CD} 4^{+}$and $\mathrm{CD} 8^{+} \mathrm{T}$ cell subsets, we analyzed the cell fractions directly ex vivo by multi-color staining of a set of chemokine receptors (CCR7, CXCR3, CCR4, CCR6 and CCR10). ${ }^{21}$ Comparison of immunological parameters to control donors reflected an altered composition of the T cell compartment of BSRC patients indicating that the disease could be monitored via phenotyping peripheral T cell populations. We furthermore correlated the resulting immunological phenotype with the clinical presentation of each BSRC patient on the sample collection day, intending to identify different immune signatures during clinical active or inactive state of disease.

\section{Methods}

\section{Patients and study design}

In our pilot study, we examined 11 patients (22 eyes) with BSRC. The diagnosis of BSRC was made according to the research criteria of the international consensus conference. ${ }^{28}$ All patients with BSRC were previously tested for HLAA29.2 allele positivity. Clinical examination was performed using multimodal standard imaging techniques, as previously published. ${ }^{27}$ On the clinical examination day, visual acuity (VA), findings on slit lamp, indirect fundoscopy, spectral-domain optical coherence tomography (SD-OCT), fluorescein angiography (FA), and indocyanine green angiography (ICGA) were recorded. ICGA images were analyzed for the presence of hypofluorescent dots. ${ }^{27}$ SD-OCT, FA, and ICGA were performed on the spectral-domain OCT (SPECTRALIS ${ }^{\circledR}$, Heidelberg Engineering, Heidelberg, Germany). Fundus photographs were taken with Zeiss FF 450+. In parallel, $30 \mathrm{~mL}$ blood was collected from each BSRC patient and subjected to flow cytometric analysis of surface markers for inflammatory $T$ cell subsets and for their effector function upon polyclonal stimulation. The study was performed in accordance with the Declaration of Helsinki and approved by the local ethics committee (Ethikkomission der Charité- Universitätsmedizin Berlin) (EA2/148/15). Written informed consent was obtained from each participating patient before blood sampling.

\section{Clinical parameters used for the study}

The ocular inflammation was classified according to the Standardization of Uveitis Nomenclature (SUN) Working Group criteria. ${ }^{28,29}$ Data of indirect fundoscopy were used to determine the degree of cell infiltration e.g. vitreous haze $(\mathrm{VH})$ per eye. The degree of $\mathrm{VH}$ is classified as no infiltration $=0$, very mild $=0.5$, mild $=1$, moderate $=2$ and severe $=3$. SD-OCT was used to determine deep resolution structural information, such as cystoid macular edema (CME) and central retinal thickness (CRT). CME was defined as the presence of intraretinal or subretinal fluid. FA and ICGA were simultaneously performed and analyzed by using proposed scoring system to classify the active intraocular 
inflammatory process by retinal, macular and optic disc leakage. ${ }^{30,31}$ The degree of retinal leakage is classified as focal $=1$ or diffuse $=2$. The degree of macular leakage is classified as no perifoveal hyperfluorescence $=0$, incomplete perifoveal hyperfluorescence $=1$, mild $360^{\circ}$ hyperfluorescence $=2$, moderate $360^{\circ}$ hyperfluorescence $=3$, severe $360^{\circ}$ hyperfluorescence with the hyperfluorescent area being approximately 1.5 disc diameter across $=4{ }^{30,31}$ ICGA images were analyzed for the presence of hypofluorescent dots as sign for activity. ${ }^{32}$ Four out of 11 patients were repeatedly (2-time points) analyzed in order to follow the course of the disease. The control cohort consisted of healthy mid-aged as well as elderly volunteers with Fuchs Endothelial Corneal Dystrophy (FECD) $(n=14)$.

\section{Blood sampling}

Per study participant, $30 \mathrm{~mL}$ blood was collected in Li-heparin vacutainer tubes (BD, USA). Blood was diluted 1:1 with PBS/BSA and peripheral blood mononucleated cells (PBMCs) were separated by Bicoll-Paque (Biochrom, Germany) gradient centrifugation (20 min, 850xg at RT).

\section{PBMC culture}

In-vitro polyclonal activation was performed with fresh PBMCs that rested overnight in culture medium, consisting of RPMI 1640 (Gibco, USA) supplemented with 10\% heat inactivated human AB-serum (Lonza, Switzerland), 100U penicillin and $0.1 \mathrm{mg} / \mathrm{ml}$ streptomycin (Biochron, Germany). $5 \times 10^{6} \mathrm{PBMCs} / \mathrm{ml}$ were either left unstimulated and served as control or were stimulated in culture medium supplemented with $10 \mathrm{ng} / \mathrm{ml} \mathrm{PMA}$ and $1 \mu \mathrm{g} / \mathrm{ml}$ ionomycin (Sigma, Germany) for $6 \mathrm{~h}$ in an incubator $\left(37^{\circ} \mathrm{C}\right.$, humidified $\left.5 \% \mathrm{CO}_{2}\right)$. After $2 \mathrm{~h}$ of stimulation, $2 \mu \mathrm{g} / \mathrm{ml}$ Brefeldin A (Sigma, Germany) was added to all samples.

\section{Flow cytometry}

$1 \times 10^{7}$ PBMCs were labelled ex vivo on the cell surface with fluorescent monoclonal antibodies titrated to their optimal concentration: CD4-A700 (RPA-T4, BD, USA), CD8-V500 (RPA-T8, BD, USA) and CD45RA-PeCy7 (HI100, Biolegend, USA), CCR7-A488 (G043H7, Biolegend, USA), CCR4-PerCpCy5.5 (L291H4, Biolegend, USA), CCR6-BV605 (G03E3, Biolegend, USA), CCR10-PE (6588-5, Biolegend, USA), and CXCR3-A647 (G025H7, Biolegend, USA) for 15 min in the dark. For dead cell exclusion, $0.4 \mu \mathrm{M}$ DAPI was added directly prior measurement. All stainings were performed in the presence of $1 \mathrm{mg} / \mathrm{ml}$ Beriglobin (CSL Behring, USA). All steps were performed at room temperature.

For the detection of cytokines, stimulated and unstimulated PBMCs were washed twice with PBS and dead cells were subsequently stained with FarRed (Molecular Probes, USA) for 20 min in the dark. Following surface staining antibodies were added during the last 10 min of the staining: CD3-PE (UCHT 1, home), CD8-V500 (RPA-T8, BD, USA), CD4-A700 (RPA-T4, BD, USA), CD4-PerCpCy5.5 (OKT 4), CD45RO-BV785 (UCHL1), CD45RA-PeCy7 (HI100), CCR7-A488 $(\mathrm{G} 043 \mathrm{H} 7)$ followed by fixation and permeabilization with FACS-lysing/-perm2 solution (BD, USA) according to the manufacturer's protocol. Intracellular staining was conducted for $30 \mathrm{~min}$ in the dark with: CD40L-APC (5C8, Miltenyi, Germany), IFN-Y-A700 (B27, BD, USA), IL-17-APCCy7 (BL168, Biolegend, USA), IL-22-ef1450 (22URTI, eBioscience, USA), IL-2-PeCy7 (MQ1-17H12, Biolegend, USA), CD3-efl605 (OKT3, eBioscience, USA), TNF-a-PerCpCy5.5 (MAb11, Biolegend, USA), and CD69-PB (FN50, Biolegend, USA). $2.5 \times 10^{6}$ PBMCs were recorded on LSR II (BD, USA) flow cytometer, except unstimulated controls where $1 \times 10^{6}$ PMCs were recorded. LSR II was equipped with 4 lasers and 15 fluorescent detection channels. Rainbow beads were acquired prior to each measurement, ensuring constant laser quality. Acquired FACS data sets were analysed with FlowJo® version 10 (Tree Star, USA).

\section{Statistical analysis}

All data were analyzed using R® or GraphPad Prism 7 (GraphPad Software, La Jolla, CA). We used Student's t-test with Welch's correction, Mann Whitney U Test, and Spearman's $\rho$ correlation coefficient. A significant $p$-value was 
defined as $p \leq 0.05$. Particular test usage is indicated in the figure legends.

\section{Results}

\section{Patient characteristics}

Eleven patients with BSRC were examined at the Department of Ophthalmology, Charité Berlin. All patients were Caucasians and showed HLA-A29.2 positivity (100\%). Seven patients were female $(64 \%, 7 / 11)$, and the mean age was $60+/-9$ years (range 39-73) on the examination day. All 11 patients were healthy at the day of blood collection, except for their ocular symptoms. The control group consisted of healthy mid-aged volunteers and elderly subjects with FECD ( $n=14$, mean 60 years).

\section{Group Classification}

Based on previous studies, BSRC patients were classified in two groups: active and inactive disease. ${ }^{27}$ We identified 10 eyes of 5 patients with retinal vascular leakage, hyperfluorescence of the disc in FA, and manifestation of dark dots in ICGA, which were summarized into the active intraocular inflammatory group. 12 eyes of 6 patients demonstrated no retinal vascular leakage in FA and dark dots in ICGA, and were thus graded as inactive intraocular inflammatory group. These eyes revealed an inactive, end-stage disease because of altered vascular architecture and retinal thinning. ${ }^{27}$ Three eyes revealed a chronic CME, which last over years without any signs of vasculitis or choroiditis, so that these patients were graded as inactive. The patients of the inactive disease cohort have an average disease duration of 13 years compared to 4 years in patients with active disease. Most of the patients were on systemic immunosuppressive treatments: antimetabolites - mycophenolate mofetil (MMF): 4/11 (36\%), calcineurin inhibitor ciclosporine A (CsA): 1/11 (9\%), prednisolone < $10 \mathrm{mg}$ per day: 1/11 (9\%), and MMF combined with prednisolone< $10 \mathrm{mg}$ per day: $2 / 11$ (18\%). A total of 4 of 11 patients (36\%) received adalimumab, a tumor necrosis factor-alpha inhibitor. More details about patients' characteristics are presented in Table 1. 
Table 1

Patients characteristic

\begin{tabular}{|c|c|c|c|c|c|c|c|c|}
\hline Patient & Age & Gender & $\begin{array}{l}\text { Year of } \\
\text { diagnosis }\end{array}$ & $\begin{array}{l}\text { Disease } \\
\text { status }\end{array}$ & Prior treatment & $\begin{array}{l}\text { Current } \\
\text { treatment }\end{array}$ & $\begin{array}{l}\text { New } \\
\text { switched } \\
\text { Treatment }\end{array}$ & Comorbidity \\
\hline 1 & 66 & $\mathrm{~F}$ & 2006 & inactive & Corticosteroids & MFF & Adalimumab & \\
\hline 2 & 58 & M & 2003 & inactive & Corticosteroids & CSA & Adalimumab & $\begin{array}{l}\text { Diabetes } \\
\text { mellitus Typ } \\
\text { II }\end{array}$ \\
\hline 3 & 59 & M & 2008 & active & $\begin{array}{l}\text { Corticosteroids, } \\
\text { CSA }\end{array}$ & MFF & Adalimumab & \\
\hline 4 & 65 & $\mathrm{~F}$ & 2009 & inactive & $\begin{array}{l}\text { Corticosteroids } \\
\text { CSA }\end{array}$ & MMF & Adalimumab & \\
\hline 5 & 63 & $\mathrm{~F}$ & 1999 & inactive & $\begin{array}{l}\text { Corticosteroids } \\
\text { CSA } \\
\text { MMF } \\
\text { Adalimumab }\end{array}$ & - & - & \\
\hline 6 & 56 & $F$ & 2015 & active & $\begin{array}{l}\text { Corticosteroids } \\
\text { CSA }\end{array}$ & MMF & - & \\
\hline 7 & 72 & $\mathrm{~F}$ & 1994 & inactive & Corticosteroids & MMF & - & \\
\hline 8 & 73 & M & 2015 & inactive & MFF & MMF & - & \\
\hline 9 & 59 & $\mathrm{~F}$ & 2008 & active & Corticosteroids & - & - & \\
\hline 10 & 57 & $\mathrm{~F}$ & 2016 & active & Corticosteroids & - & - & \\
\hline 11 & 39 & $M$ & 2015 & active & Corticosteroids & CSA & - & $\begin{array}{l}\text { Beta- } \\
\text { Thalassemia }\end{array}$ \\
\hline
\end{tabular}

\section{Peripheral $\mathrm{CD}^{+} \mathrm{T}_{\mathrm{EMRA}} \mathrm{T}$ cell populations are enriched in patients with inactive BSRC disease}

To achieve an efficient discrimination of peripheral naïve and memory $T$ cell phenotypes and to delineate the composition of inflammatory subsets among $C D 4^{+}$helper $\left(T_{H}\right)$ and cytotoxic $C D 8^{+} T$ cells $\left(T_{C}\right)$ of our BSRC cohort, we examined the expression of 6 different surface markers by flow cytometry (CCR7, CD45RA, CXCR3, CCR4, CCR6, CCR10) in freshly isolated peripheral T cells.

The averaged proportions of $\mathrm{CD}^{+}(55 \%)$ and $\mathrm{CD}^{+}(21 \%) \mathrm{T}$ cells among living lymphocytes were similar between the BSRC patient group and age-matched controls ( $49.6 \%$ and $19.8 \%$; data not shown). According to the expression of CD45RA and CCR7, naïve, and memory $T$ cell subsets were identified within the $\mathrm{CD} 4^{+}$and $\mathrm{CD} 8^{+} \mathrm{T}$ cell compartments, respectively: $C C R 7^{+} C D 45 R A^{+}$naïve $T$ cells, $C C R 7^{+} C D 45 R A^{-}$central memory $T$ cells $\left(T_{C M}\right), C C R 7^{-} C D 45 R A^{-}$effector memory cells $\left(T_{E M}\right)$ and CCR7 ${ }^{-}$CD 45RA ${ }^{+} T_{\text {EMRA }}$ cells (gating strategy exemplified in Fig. $1 A$ ). Analysis of naïve vs. $T_{C M}$, 
$T_{E M}$, and $T_{E M R A}$ memory $T$ cell populations revealed significant differences in naïve vs. terminally differentiated $T_{E M R A}$ $\mathrm{CD}^{+} \mathrm{T}$ cells within the BSRC group (Fig. 1B, C). Although median frequencies plus ranges of $\mathrm{T}_{\mathrm{EMRA}} \mathrm{CD} 8^{+} \mathrm{T}$ cells were similar between BSRC patients and the aged-matched control group (BSRC: median: 48\% (30-80); control: median: $51.8 \%(14-87)$ ), intragroup differences of the BSRC cohort were identified when disease activity was considered. Compared to the active disease group and treatment independent (data not shown), BSRC patients with inactive disease displayed an increased $T_{\text {EMRA }}$ population in blood (median active: $39.6 \%$ to inactive: $64.1 \%, p=0.01 *$ ). The population of CCR7-/CD45RA- was in one inactive patient absent, therefore the Figs. 1B and 1D include $n=5$ inactive patients. But this patient had CCR7+/CDRA- cells, so further analysis could be conducted. Although not significant, we observed a tendency for an even higher median frequency of the CD8 ${ }^{+} \mathrm{T}_{\text {EMRA }}$ population in inactive eyes (median: $64.1 \%$ ) compared to the control group (median: 51.8\%) (Fig. 1B, $\mathrm{p}=0.08$ ), suggesting a trend for accumulation of

$\mathrm{T}_{\text {EMRA }}$ cells in disease-inactive episodes of BSRC disease. We observed a correlation of CD8 $+\mathrm{T}_{\text {EMRA }}$ frequencies with age in the control group ( $\rho=0.7357, p=0.0037 * *$, Fig. 1D), but not in the BSRC group $(\rho=0.4376, p=0.132 n s$; Fig. 1D). The BSRC patients belong to the same age group, and hence the differences in CD $8+T_{\text {EMRA }}$ frequencies can be attributed rather to disease state. $5 / 5$ data points of the inactive group led profoundly over the $\mathrm{R}^{2}$ linear regression line, whereas $4 / 5$ data points of the active group led under the $\mathrm{R}^{2}$ linear regression line, suggesting the possibility that $\mathrm{CD}^{+} \mathrm{T}_{\mathrm{EMRA}} \mathrm{T}$ cells indicate disease status of BSRC disease (Fig. 1D). Extended analysis of possible correlations of frequencies of $\mathrm{CD}^{+} \mathrm{T}_{\mathrm{EMRA}}$ cells with clinical parameters of BSRC patients in a volcano plot showed a negative correlation with the presence of intraocular vasculitis $(\rho=-0.7312, p=0.0317 *$, Fig. $1 \mathrm{C})$, but correlated only weakly negative and insignificantly with other active disease parameters, such as the presence of intraocular VH $(\rho=-0.2470$, $p=0.4888 n s), \operatorname{CRT}(\rho=-0.2969, p=0.4697 n s)$, retinal leakage $(\rho=-0.3290, p=0.3476 n s), \operatorname{CME}(\rho=0.5376, p=$ $0.1333 n s)$, macular leakage $(\rho=0.4181, p=0.2333 n s)$, optic disc leakage $(\rho=0.0789, p=0.8723 n s)$, and disease duration $\left(\rho=0.4451, p=0.1982 \mathrm{~ns}\right.$ ) (Fig. 1C). In contrast to the increased CD ${ }^{+} \mathrm{T}_{\text {EMRA }}$ cell population observed in inactive BSRC patients, active BSRC patients showed a significantly increased naïve CD $8^{+} \mathrm{T}$ cell population in blood (median 34.9\%) compared to disease-inactive BSRC patients $(11.8 \%, p=0.0149 *)$ and controls $(22 \%, p=0.0328 *)$ (data not shown), that correlated significantly positive with vasculitis $(\rho=0.7311, p=0.0317 *$; Fig. $1 \mathrm{C})$. Furthermore, we found weak positive correlations with clinical measures of active disease: $\mathrm{VH}(\rho=0.4434, p=0.1984, n s)$, retinal, and macular leakage $(\rho=0.3906, p=0.2626, n s)$. Moreover, we noted a similar tendency for increased proportions of $\mathrm{T}_{\text {EMRA }} \mathrm{CD} 4^{+} \mathrm{T}$ cells in inactive BSRC patients (median: $\left.1.7 \%\right)$ compared to active BSRC patients $(0.5 \%)$ and controls $(0.9 \%)$ (data not shown) that was again independent from treatment and trended towards a similar correlation pattern as observed for CD8 ${ }^{+} \mathrm{T}_{\text {EMRA }}$ (Fig. 1C).

\section{Signs of an imbalanced $\mathrm{T}_{\mathrm{H}} 1 / \mathrm{T}_{\mathrm{H}} 2$ subsets in patients with active eyes}

To assess the potential contribution of different $C D 4^{+}$and $C D 8^{+} T$ cell subsets in BSRC pathogenesis, we further analyzed the circulating $T$ cell memory compartment for inflammatory subsets. The combined CD45RA ${ }^{-} T_{C M}$ and $T_{E M}$ memory $T$ cell gates were further subdivided into the $C D 4^{+}$helper and cytotoxic $C D 8^{+} T$ cell subsets $T_{H} 1 / T_{C} 1$, $\mathrm{T}_{H} 2 / \mathrm{T}_{\mathrm{C}} 2, \mathrm{~T}_{\mathrm{H}} 17.1 / \mathrm{T}_{\mathrm{C}} 17.1, \mathrm{~T}_{H} 17 / \mathrm{T}_{\mathrm{C}} 17, \mathrm{~T}_{\mathrm{H}} 22 / \mathrm{T}_{\mathrm{C}} 22$ using chemokine receptors: CXCR3, CCR4, CCR6, and CCR10 (Fig. 2A and B) [26]. Within the BSRC patient group having active disease, we observed tendency for a predomination of $\mathrm{CXCR}^{+} \mathrm{T}$ cell subsets $\mathrm{T}_{\mathrm{H}} 1 / \mathrm{T}_{\mathrm{C}} 1, \mathrm{~T}_{\mathrm{H}} 17.1 / \mathrm{T}_{\mathrm{C}} 17.1$ among both, $\mathrm{CD} 4^{+}$(median $\mathrm{T}_{\mathrm{H}} 1: 23.1 \%$ \& $\mathrm{T}_{H^{17}} 17.1: 18.2 \% ; p=n s$ ) and $\mathrm{CD}^{+} \mathrm{T}$ cell fractions (median $\mathrm{T}_{\mathrm{C}} 1: 52.6 \%$ \& $\mathrm{T}_{\mathrm{C}} 17.1: 8 \% ; p=n s$ ) compared to the control group (median $\mathrm{T}_{\mathrm{H}} 1$ : 19.7\% \& $T_{H}$ 17.1: 14.65\%; $T_{C} 1: 40.1 \%$ \& $T_{C} 17.1: 4.1 \%$ ) (Fig. 2C-E). In contrast, BSRC patients with inactive disease 
rather resembled the frequencies of inflammatory $T$ cell subsets of control probands (median $T_{H} 1: 18.5 \%$ \& $T_{H} 17.1$ : 13.4\%; $\left.T_{C} 1: 39.7 \% \& T_{C} 17.1: 3.36 ; p=n s\right)$, except a slightly increased frequency of $T_{C} 17$ cells (median $1.08 \%$ ) compared to the control group (median $0.56 \% ; p=n s$ ). Furthermore, we found tendencies for a skewed $T_{H} 1 / T_{H} 2$ ratio in the active BSRC patient group, which was absent in the inactive BSRC patient group (Fig. 2D). Correlation of $\mathrm{CXCR}^{+}$inflammatory $\mathrm{T}$ cell populations $\mathrm{T}_{\mathrm{H}} 1, \mathrm{~T}_{\mathrm{C}} 1$, and $\mathrm{T}_{\mathrm{C}} 17.1$ with clinical parameters revealed positive correlations in the volcano plot for these subsets with clinical parameters of an ongoing inflammatory episode in BSRC eyes, such as retinal leakage, optic disc leakage, and the degree of severity of the disease (Fig. 2F), although lacking significance.

\section{Analysis of T cell effector function}

Next, we compared the overall effector function of peripheral memory T cells of BRC patients and the control group upon in vitro polyclonal stimulation using phorbol 12-myristate 13-acetate (PMA) and ionomycin. We assessed the capacity of the memory $T$ cell pool to produce effector cytokines by intracellular staining of IFN- $y$ and TNF- $a$ (mainly secreted cytokines of $T_{H} 1 / T_{C} 1$ and $T_{H} 17.1 / T_{C} 17.1$ polarized cells); IL-2, IL-4 ( $\left.T_{H} / T_{C} 2\right)$, IL-17 ( $T_{H} 17.1 / T_{C} 17.1$; $\left.\mathrm{T}_{\mathrm{H}} 17 / \mathrm{T}_{\mathrm{C}} 17 ; \mathrm{T}_{\mathrm{H}} 22 / \mathrm{T}_{\mathrm{C}} 22\right)$, and IL-22 $\left(\mathrm{T}_{\mathrm{H}} 22 / \mathrm{T}_{\mathrm{C}} 22\right)$ according to the preceding ex vivo characterization [26]. The evaluation of the intracellular staining of different cytokines derived from the $\mathrm{CD} 45 \mathrm{RO} \mathrm{C}^{+} \mathrm{CD} 4^{+}$and $\mathrm{CD} 8^{+}$memory $\mathrm{T}$ cell populations (Fig. 3A-D) indicated a reduced potential of BSRC patients to produce certain effector cytokines upon polyclonal stimulation compared to the control group (upper rows compared to lower), which was independent of disease activity (data not shown). Especially the levels of IFN-y $\left(p=0.02^{*}\right)$, IL-2 $\left(p=0.03^{*}\right)$, and IL-22 $\left(p=0.04^{*}\right)$ of $\mathrm{CD} 45 \mathrm{RO}^{+} \mathrm{CD}^{+}$memory T cells were significantly decreased (Fig. 3B). The amount of TNF-a reached a close to significant difference $(p=0.07)$ between the patient cohort and the control probands. This trend continued in the $\mathrm{CD} 45 \mathrm{RO}^{+} \mathrm{CD}^{+} \mathrm{T}$ cell population of the BSRC patient group. Here, we observed also significantly lower IFN- $\gamma(p=$ $\left.0.007^{* *}\right)$, TNF-a $\left(p=0.01^{*}\right)$, and IL-4 $\left(p=0.03^{*}\right)$ levels, compared to the control group (Fig. 3D).

\section{Discussion}

This pilot study represents a deep-phenotyping of various inflammatory memory $\mathrm{T}$ cell fractions in the peripheral blood of BSRC patients with active and inactive stage of disease and their comparison to age-matched controls. We evaluated the composition of the circulating T cell compartment directly ex vivo and furthermore assessed the capacity of the memory $T$ cell compartment to exert effector function upon polyclonal stimulation by measuring cytokine secretion profiles using flow cytometry.

First, we identified a slight increase of CD45RA-expressing $C D 8^{+} T$ cells $\left(T_{E M R A}\right)$ in blood of the inactive, end-stage group compared to the active group, although our sample size is too small to draw clear conclusions. Several studies characterized $\mathrm{T}_{\text {EMRA }}$ cells as low IL-2 producer and high IFN- $y$ and TNF-a secretor, accompanied by a high cytotoxicity and a high sensitivity to apoptosis. ${ }^{33-35}$ Expansion of pathogenic $T_{\text {EMRA }}$ cells have been proven in a variety of diseases from autoimmunity (multiple sclerosis, lupus) to allotransplantation and bone regeneration. ${ }^{36-39}$ Yap et al. reported that expansion of $\mathrm{T}_{\mathrm{EMRA}} \mathrm{CD} 8$ can be detected in kidney-transplant recipients despite a long-term stable graft function and that such expansion is associated with a two-fold higher risk of kidney graft dysfunction. ${ }^{40}$ Accumulation of $\mathrm{CD}^{+} \mathrm{T}_{\mathrm{EMRA}}$ cells is also associated with age, chronic antigen stimulation, and immune system senescence, which is often interpreted as a hallmark of aging and a marker of exhausted immune system. ${ }^{41-45}$ Our data did not show any correlation between $C D 8^{+} T_{\text {EMRA }} T$ cell abundance and age, but the frequencies of CD $8^{+} T_{E M R A}$ cells correlated negatively with the presence of vasculitis e.g. the extent of intraocular inflammation. It can be assumed that a high amount of $\mathrm{T}$ cells with $\mathrm{CD} 8^{+} \mathrm{T}_{\text {EMRA }}$ phenotype describe an impaired immune function in the eye 
likely as a consequence of the recurrent and constant inflammatory episodes which are described in BSRC. This raises the question of whether $\mathrm{CD} 8^{+} \mathrm{T}_{\mathrm{EMRA}}$ is associated with a higher risk of worse manifestation of BSRC or it could be an indicator for a poor prognostic outcome due to already a rarefication of the vessels and thinning of the retina. Reinke et al. demonstrated that delayed fracture healing significantly correlated with enhanced levels of CD8 $T_{\text {EMRA }}$ in peripheral blood. ${ }^{39}$ These cells seem to be directly involved in the pathogenesis in poor healing. ${ }^{44} \mathrm{CD} 8^{+} \mathrm{T}_{\text {EMRA }}$ might be exhausted, senescent, and poorly proliferative T cells that display several functional abnormalities.

Thus, $C D 8^{+} \mathrm{T}_{\text {EMRA }}$ cells could be probably proposed as a biomarker that describes an advanced BSRC disease state. Further prospective studies are necessary to investigate whether $C D 8^{+} \mathrm{T}_{\text {EMRA }} T$ cells occur only in inactive, burned-out patients or it is also found in newly diagnosed patients as a potential risk factor.

Furthermore, the clear HLA association in BSRC implies a pivotal role of T cells in disease development and/or progression. ${ }^{6}$ Histopathological descriptions characterized lymphocytic aggregations with their foci in the deep choroid, in the optic nerve head, and along the retinal vasculature. ${ }^{2}$ In addition, analyses of eye infiltrates derived from vitreous fluidics revealed the presence of retina or choroid-reactive intraocular $\mathrm{CD} 4^{+}$and $\mathrm{CD} 8^{+} \mathrm{T}$ cells in disease-active BSRC eyes, suggesting their role in ongoing auto-inflammatory processes. ${ }^{8,21}$ Expanded $T$ cell clones showed effector memory phenotype and were able to secrete the classical $T_{H} 1$-cytokine profile (IL-2, IFN- $y$ and TNF-a) upon CD3 stimulation. ${ }^{8}$ The leukocytes include mostly ocular specific T cells that synergistically contribute to local inflammation and tissue damage. ${ }^{46,47}$ Usually, the exposure of the highly immunogenic ocular antigens (for example retinal S-antigen) to T cells is prevented by the retina-blood barrier and the immune privileged environment of the eye. When these barriers breach, ocular specific T cells may migrate into the eye and induce tissue damages. Different reports demonstrated intraocular T cell reactivity to retinal and choroidal lysate, but the antigen in BSRC is currently still unknown. ${ }^{8}$ However, most of the studies classify the T cells by distinct cytokines. 3,21,22 Due to reoccurring episodes and probably exhausted T cells, it is questionable whether measuring the effector function by cytokine profile analysis is a suitable approach to classify the T cell function of uveitis patients. Here, the chemotactic receptors might give additional or even more precise information about the abundance and the composition of certain peripheral T cell compartments in BSRC disease. In general, chemotactic gradients can be established elsewhere in the body by many different cell types in consequence to immunological activation. The expression of a certain set of chemokine receptors makes $T$ cells restricted to specific chemokines, thus ensuring correct guidance and compartmentalization of antigen-primed T cells as demonstrated by Loyal et al. ${ }^{26}$. Our results show a trend for the predomination of the $\mathrm{CXCR}^{+} \mathrm{T}$ cell subsets $\mathrm{T}_{H} 1 / T_{C} 1$ in both, $C D 4^{+}$and $C D 8^{+} T$ cell fraction. The $T 1 / T 2$ imbalance indicate changes in the immune function and has been described in experimental autoimmune uveitis/uveoretitinitis (EAU). ${ }^{48}$ Therefore, T1/T2 ratio may serve as an indicative marker for BSRC disease activity. Of note, most of the studies measure the concentration of cytokine as secreted by $T_{H} 1$ and $T_{H} 2$ cells while we demonstrate a possible contribution of $\mathrm{CD}^{+} \mathrm{T}$ cells as well as gradually impaired cytokine secretion highlighting the importance of an ex vivo cell classification. Moreover, recent studies revealed a prominent role of $\mathrm{T}_{\mathrm{H}^{1}} 17$ cells that drive chronic inflammation in T cell-associated immune disorders including non-infectious uveitis and BSRC. ${ }^{22,49}$ In BSRC a subset of CD $8^{+}$T cells was reported that express the endothelial adhesion molecule 'MCAM' (CD146) and secrete IL-17. ${ }^{23}$ This suggest that $\mathrm{T}_{\mathrm{H}} 17$ and $\mathrm{T}_{\mathrm{C}} 17$ cells may concomitantly contribute to the $\mathrm{IL}-17$ mediated pathogenesis. It would be of interest to evaluate IL-17 production of intraocular T cells in BSRC, since retinal IL-17 production CD $8^{+} \mathrm{T}$ cells in EAU has been demonstrated by Peng et al. ${ }^{50}$ Tc17 cells might be able to target HLA-molecules that present ERAP2 trimmingdependent epitopes, linking the HLA I presentation with IL-17 associated immunity in BSRC. ${ }^{7}$ Our data did not reveal a 
clear tendency for $T_{H} 17 / T_{C} 17$ phenotypes. However, the current role of IL-17 in BSRC is not clarified, but few studies showed that IL-17 has protective effects during inflammation. ${ }^{51-53}$

Finally, we observed impaired cytokine production of $\mathrm{CD} 4^{+}$and $\mathrm{CD} 8^{+}$memory $\mathrm{T}$ cells in BSRC patients regardless of their treatment and stage of disease. These results support in the literature reported elevated levels of IL-23, IL1- $\beta$, IL6 , and TGF- $\beta$ in serum of BSRC patients which might be associated with the T cell exhaustion. ${ }^{24,25}$ Molins et al. demonstrated elevated levels of IL-17A in patients with BSRC in remission with and without immunomodulatory treatment. Patients who were not receiving immunomodulatory treatment had significantly higher levels of circulating IL-23 and TGF- $\beta 1$ than patients under immunomodulatory treatment or healthy subjects. ${ }^{54}$

Of course, many studies reported about immune perturbations in the peripheral blood of uveitis patients and the immune changes in the peripheral blood not necessarily mirror the changes in the eye. But immune privilege is not interpreted as a lack of immunosurveillance. ${ }^{55-57}$ It is known that immune cells visit healthy sites of immune privilege. ${ }^{58,59}$

\section{Conclusion}

To sum up, we observed more $C D 8^{+} \mathrm{T}_{\mathrm{EMRA}}$ in inactive BSRC patients and significantly less in active patients. Therefore, high frequencies of $C D 8^{+} T_{\text {EMRA }} T$ cells could be an indicator for a poor prognostic outcome in advanced stage of the disease. The T1/T2 imbalance in BSRC may indicate autoimmune processes and decreased cytokine levels in the periphery are probably caused by immunosuppression or exhaustion of the memory $\mathrm{T}$ cell subsets.

The size of the herein analyzed patient pool is too small for definitve conclusions. Therefore, immunological studies with higher patient numbers are required for a deeper understanding of the T cell contribution to BSRC development and the potential for targeted immunotherapy. However, our results offer new insights into the immunological pathophysiology of BSRC disease and may help in defining new biomarkers for monitoring for this potentially blinding disease. Accordingly, we propose to distinguish these cells ex vivo based on the expression of chemokine receptor instead of functional analyses.

\section{Declarations}

\section{Acknowledgements}

This abstract was presented as a poster at the German Ophthalmology Society 2019 and was awarded a prize for the best poster.

\section{Funding}

Dr. Dominika Pohlmann is participant in the BIH Charité Clinician Scientist Program funded by the CharitéUniversitätsmedizin Berlin and the Berlin Institute of Health.

\section{References}

1. Minos E, Barry RJ, Southworth S, Folkard A, et al. Birdshot chorioretinopathy: current knowledge and new concepts in pathophysiology, diagnosis, monitoring and treatment. Orphanet J Rare Dis. 2016;11(1):61. doi: 10.1186/s13023-016-0429-8. 
2. Gaudio PA, Kaye DB, Crawford JB. Histopathology of birdshot retinochoroidopathy. Br J Ophthalmol. 2002;86(12):1439-41. doi: 10.1136/bjo.86.12.1439.

3. Kuiper JJ, Rothova A, Schellekens PA, Ossewaarde-van Norel A, et al. Detection of choroid- and retina-antigen reactive $\mathrm{CD} 8(+)$ and $\mathrm{CD} 4(+)$ T lymphocytes in the vitreous fluid of patients with birdshot chorioretinopathy. Hum Immunol. 2014;75(6):570-7. doi: 10.1016/j.humimm.2014.02.012.

4. Kuiper JJ, Mutis T, de Jager W, de Groot-Mijnes JD, Rothova A. Intraocular interleukin-17 and proinflammatory cytokines in HLA-A29-associated birdshot chorioretinopathy. Am J Ophthalmol. 2011;152(2):177 - 82.e1. doi: 10.1016/j.ajo.2011.01.031.

5. Kuiper J, Rothova A, de Boer J, Radstake T. The immunopathogenesis of birdshot chorioretinopathy; a bird of many feathers. Prog Retin Eye Res. 2015;44:99-110. doi: 10.1016/j.preteyeres.2014.11.003.

6. Baarsma GS, Priem HA, Kijlstra A. Association of birdshot retinochoroidopathy and HLA-A29 antigen. Current Eye Research. 1990;9(sup1):63-8. doi: 10.1186/s13023-016-0429-8.

7. Kuiper JJW, Setten JV, Devall M, Cretu-Stancu M, Hiddingh S, et al. Functionally distinct ERAP1 and ERAP2 are a hallmark of HLA-A29-(Birdshot) Uveitis. Hum Mol Genet. 2018;27(24):4333-43. doi: 10.1093/hmg/ddy319.

8. You C, Meese H, Stephenson A, Montieth A, Ma L, Hernandez M, et al. Outcomes of "Early" Withdrawal of Corticosteroid Sparing Immunomodulatory Therapy for Birdshot Retinochoroidopathy. Ocular Immunology and Inflammation. 2019;27(7):1165-1173. doi: 10.1080/09273948.2018.1506040

9. Vitale AT, Rodriguez A, Foster CS. Low-dose cyclosporine therapy in the treatment of birdshot retinochoroidopathy. Ophthalmology. 1994;101(5):822-31. doi:10.1016/s0161-6420(13)31254-8.

10. Kiss S, Ahmed M, Letko E, Foster CS. Long-term follow-up of patients with birdshot retinochoroidopathy treated with corticosteroid-sparing systemic immunomodulatory therapy. Ophthalmology. 2005;112(6):1066-71. doi: 10.1080/09273948.2019.1641610.

11. Becker MD, Wertheim MS, Smith JR, Rosenbaum JT. Long-Term Follow-Up of Patients with Birdshot Retinochoroidopathy Treated with Systemic Immunosuppression. Ocular Immunology and Inflammation. 2005;13(4):289-93. doi: 10.1001/jamaophthalmol.2013.6235.

12. Huis Het Veld PI, van Asten F, Kuijpers RWAM, Rothova A, et al. Adalimumab therapy for refractory birdshot chorioretinopathy. Retina. 2019;39(11):2189-2197. doi: 10.1097/IAE.0000000000002281.

13. Steeples LR, Spry P, Lee RWJ, Carreño E. Adalimumab in refractory cystoid macular edema associated with birdshot chorioretinopathy. Int Ophthalmol. 2018;38(3):1357-1362. doi: 10.1007/s10792-017-0592-5.

14. Calvo-Río V, Blanco R, Santos-Gómez M, Díaz-Valle D, et. al. Efficacy of Anti-IL6-Receptor Tocilizumab in Refractory Cystoid Macular Edema of Birdshot Retinochoroidopathy Report of Two Cases and Literature Review. Ocul Immunol Inflamm. 2017;25(5):604-609. doi: 10.1080/09273948.2016.1231331.

15. Doycheva D, Jägle H, Zierhut M, Deuter C, Blumenstock G, Schiefer U, et al. Mycophenolic acid in the treatment of birdshot chorioretinopathy: long-term follow-up. British Journal of Ophthalmology. 2015;99(1):87-91. doi: 10.1136/bjophthalmol-2014-305535.

16. Cervantes-Castañeda RA, Gonzalez-Gonzalez LA, Cordero-Coma M, Yilmaz T, et al. Combined therapy of cyclosporine A and mycophenolate mofetil for the treatment of birdshot retinochoroidopathy: a 12-month followup. Br J Ophthalmol. 2013;97(5):637-43. doi: 10.1136/bjophthalmol-2012-302123.

17. Kagami S, Rizzo HL, Lee JJ, Koguchi Y, et al. Circulating Th17, Th22, and Th1 Cells Are Increased in Psoriasis. Journal of Investigative Dermatology. 2010;130(5):1373-83. doi: 10.1038/jid.2009.399.

18. Eastaff-Leung N, Mabarrack N, Barbour A, Cummins A, et al. Foxp3 + Regulatory T Cells, Th17 Effector Cells, and Cytokine Environment in Inflammatory Bowel Disease. Journal of Clinical Immunology. 2010;30(1):80-9. doi: 
10.1007/s10875-009-9345-1.

19. Chemin K, Gerstner C, Malmström V. Effector Functions of CD4 + T Cells at the Site of Local Autoimmune Inflammation-Lessons From Rheumatoid Arthritis. Front Immunol.2019;10:353. doi: 10.3389/fimmu.2019.00353.

20. Stromnes IM, Cerretti LM, Liggitt D, Harris RA, Goverman JM. Differential regulation of central nervous system autoimmunity by $T(H) 1$ and $T(H) 17$ cells. Nat Med. 2008;14(3):337-42. doi: 10.1038/nm1715.

21. Kuiper JJ, Emmelot ME, Rothova A, Mutis T. Interleukin-17 production and T helper 17 cells in peripheral blood mononuclear cells in response to ocular lysate in patients with birdshot chorioretinopathy. Mol Vis. 2013 Dec 27;19:2606-14. PMID: 24379648.

22. Daien V, Mura F, Martin G, Audo R, et al. Th17 and regulatory T cells are increased in blood of patients with birdshot chorioretinopathy. Acta Ophthalmol. 2017;95(2):e161-e163. doi: 10.1111/aos.12949.

23. Dagur PK, Biancotto A, Stansky E, Sen HN, Nussenblatt RB, McCoy JP. Secretion of interleukin-17 by CD $8+T$ cells expressing CD146 (MCAM). 2014;152(1-2):36-47. doi: 10.1016/j.clim.2014.01.009.

24. Yang P, Foster CS. Interleukin 21, interleukin 23, and transforming growth factor $\beta 1$ in HLA-A29-associated birdshot retinochoroidopathy. Am J Ophthalmol. 2013;156(2):400-406.e2. doi: 10.1016/j.ajo.2013.03.004.

25. Sallusto F. Heterogeneity of Human CD4 + T Cells Against Microbes. Annual Review of Immunology. 2016;34(1):317-34. doi: 10.1146/annurev-immunol-032414-112056.

26. Loyal L, Warth S, Jürchott K, Mölder F, et al. SLAMF7 and IL-6R define distinct cytotoxic versus helper memory CD8 + T cells. Nat Comm. [in press]

27. Pohlmann D, Macedo S, Stübiger N, Pleyer U, et al. Multimodal Imaging in Birdshot Retinochoroiditis. Ocul Immunol Inflamm. 2017;25(5):621-632. doi: 10.1080/09273948.2017.1375532. doi:

10.1080/09273948.2017.1375532.

28. Levinson RD, Brezin A, Rothova A, Accorinti M, et al. Research criteria for the diagnosis of birdshot chorioretinopathy: results of an international consensus conference. Am J Ophthalmol. 2006;141(1):185-7. doi: 10.1016/j.ajo.2005.08.025.

29. Jabs DA, Nussenblatt RB, Rosenbaum JT; Standardization of Uveitis Nomenclature (SUN) Working Group. Standardization of uveitis nomenclature for reporting clinical data. Results of the First International Workshop. Am J Ophthalmol. 2005;140(3):509 - 16. doi: 10.1016/j.ajo.2005.03.057.

30. Tugal-Tutkun I, Herbort CP, Khairallah M, Mantovani A. Interobserver agreement in scoring of dual fluorescein and ICG inflammatory angiographic signs for the grading of posterior segment inflammation. Ocul Immunol Inflamm. 2010;18(5):385-9. doi: 10.3109/09273948.2010.489730.

31. Tugal-Tutkun I, Herbort CP, Khairallah M; Angiography Scoring for Uveitis Working Group (ASUWOG). Scoring of dual fluorescein and ICG inflammatory angiographic signs for the grading of posterior segment inflammation (dual fluorescein and ICG angiographic scoring system for uveitis). Int Ophthalmol. 2010;30(5):539-52. doi: $10.1007 /$ s10792-008-9263-x.

32. Fardeau C, Herbort CP, Kullmann N, Quentel G, et al. Indocyanine green angiography in birdshot chorioretinopathy. Ophthalmology. 1999;106(10):1928-34. doi: 10.1016/S0161-6420(99)90403-7.

33. Sallusto F, Lenig D, Förster R, Lipp M, Lanzavecchia A. Two subsets of memory $T$ lymphocytes with distinct homing potentials and effector functions. Nature. 1999;401(6754):708-12. doi: 10.1038/44385.

34. Hamann D, Baars PA, Rep MHG, Hooibrink B, et al. Phenotypic and Functional Separation of Memory and Effector Human CD8 + T Cells. Journal of Experimental Medicine. 1997;186(9):1407-18. doi: 10.1084/jem.186.9.1407.

35. Geginat J, Lanzavecchia A, Sallusto F. Proliferation and differentiation potential of human CD8 + memory T-cell subsets in response to antigen or homeostatic cytokines. Blood. 2003;101(11):4260-6. doi: 10.1182/blood-2002- 
11-3577.

36. Salou M, Garcia A, Michel L, Gainche-Salmon A, et al. Expanded CD8 T-cell sharing between periphery and CNS in multiple sclerosis. Ann Clin Transl Neurol. 2015 Jun;2(6):609-22. doi: 10.1002/acn3.199.

37. McKinney EF, Lyons PA, Carr EJ, Hollis JL, et al. A CD8 + T cell transcription signature predicts prognosis in autoimmune disease. Nature Medicine. 2010;16(5):586-91doi: 10.1038/nm.2130.

38. Yap M, Brouard S, Pecqueur C, Degauque N. Targeting CD8 T-Cell Metabolism in Transplantation. Frontiers in Immunology. 2015;6.doi: 10.3389/fimmu.2015.00547.

39. Reinke S, Geissler S, Taylor WR, Schmidt-Bleek K, et al. Terminally differentiated CD8 ${ }^{\circ} \mathrm{T}$ cells negatively affect bone regeneration in humans. Sci Transl Med. 2013;5(177):177ra36. doi: 10.1126/scitransImed.3004754.

40. Yap M, Boeffard F, Clave E, Pallier A, et al. Expansion of highly differentiated cytotoxic terminally differentiated effector memory CD8 + T cells in a subset of clinically stable kidney transplant recipients: a potential marker for late graft dysfunction. J Am Soc Nephrol. 2014;25(8):1856-68. doi: 10.1681/ASN.2013080848.

41. Khan N, Shariff N, Cobbold M, Bruton R, et al. Cytomegalovirus seropositivity drives the CD8 T cell repertoire toward greater clonality in healthy elderly individuals. J Immunol. 2002;169(4):1984-92. doi:10.4049/jimmunol.169.4.1984.

42. Wertheimer AM, Bennett MS, Park B, Uhrlaub JL, et al. Aging and cytomegalovirus infection differentially and jointly affect distinct circulating T cell subsets in humans. J Immunol. 2014;192(5):2143-55. doi: 10.4049/jimmunol.1301721.

43. Pawelec G, Akbar A, Caruso C, Effros R, et al. Is immunosenescence infectious? Trends Immunol. 2004;25(8):406-10. doi: 10.1016/j.it.2004.05.006.

44. Larbi A, Fulop T. From "truly naïve" to "exhausted senescent" T cells: when markers predict functionality. Cytometry A. 2014;85(1):25-35. doi: 10.1002/cyto.a.22351.

45. Verma K, Ogonek J, Varanasi PR, Luther S, et al. Human CD8 + CD57- TEMRA cells: Too young to be called "old". PLoS One. 2017 May 8;12(5):e0177405. doi: 10.1371/journal.pone.0177405.

46. Caspi RR, Silver PB, Luger D, Tang J, et al. Mouse Models of Experimental Autoimmune Uveitis. Ophthalmic Research. 2008;40(3-4):169-74. doi: 10.1159/000119871.

47. Kerr EC, Copland DA, Dick AD, Nicholson LB. The dynamics of leukocyte infiltration in experimental autoimmune uveoretinitis. Prog Retin Eye Res. 2008 Sep;27(5):527-35. doi: 10.1016/j.preteyeres.2008.07.001.

48. Horai R, Caspi RR. Cytokines in Autoimmune Uveitis. Journal of Interferon \& Cytokine Research. 2011;31(10):733-44. doi: 10.1089/jir.2011.0042.

49. Bedoya SK, Lam B, Lau K, Larkin J. Th17 Cells in Immunity and Autoimmunity. Clinical and Developmental Immunology. 2013;2013:1-16. doi: 10.1155/2013/986789.

50. Peng Y, Han G, Shao H, Wang Y, Kaplan HJ, Sun D. Characterization of IL-17 + Interphotoreceptor Retinoid-Binding Protein-Specific T Cells in Experimental Autoimmune Uveitis. 2007;48(9):4153. doi: 10.1167/iovs.07-0251.

51. Li Q, Liu L, Zhang Q, Liu S, et al. Interleukin-17 Indirectly Promotes M2 Macrophage Differentiation through Stimulation of COX-2/PGE2 Pathway in the Cancer Cells. Cancer Res Treat. 2014;46(3):297-306. doi: 10.4143/crt.2014.46.3.297.

52. Liu L, Ge D, Ma L, Mei J, et al. Interleukin-17 and prostaglandin E2 are involved in formation of an M2 macrophage-dominant microenvironment in lung cancer. J Thorac Oncol. 2012;7(7):1091-100. doi: 10.1097/JTO.0b013e3182542752.

53. Nishikawa K, Seo N, Torii M, Ma N, et al. Interleukin-17 induces an atypical M2-like macrophage subpopulation that regulates intestinal inflammation. PLoS One. 2014;9(9):e108494. doi: 10.1371/journal.pone.0108494. 
54. Molins B, Mesquida M, Lee RW, Llorenç V, et al. Regulatory T cell levels and cytokine production in active noninfectious uveitis: in-vitro effects of pharmacological treatment. Clin Exp Immunol. 2015;179(3):529-38. doi: 10.1111/cei.12479.

55. Shechter R, London A, Schwartz M. Orchestrated leukocyte recruitment to immune-privileged sites: absolute barriers versus educational gates. Nature Reviews Immunology. 2013;13(3):206-18. doi: 10.1038/nri3391.

56. Wraith DC, Nicholson LB. The adaptive immune system in diseases of the central nervous system. J Clin Invest. 2012 Apr;122(4):1172-9. doi: 10.1172/JCI58648. doi: 10.1172/JCI58648.

57. Hickey WF. Basic principles of immunological surveillance of the normal central nervous system. Glia. 2001 Nov;36(2):118-24. doi: 10.1002/glia.1101.

58. Engelhardt B, Ransohoff RM. The ins and outs of T-lymphocyte trafficking to the CNS: anatomical sites and molecular mechanisms. Trends Immunol. 2005;26(9):485-95. doi: 10.1016/j.it.2005.07.004.

59. Kivisäkk P, Mahad DJ, Callahan MK, Trebst C, et al. Human cerebrospinal fluid central memory CD $4+T$ cells: evidence for trafficking through choroid plexus and meninges via P-selectin. Proc Natl Acad Sci U S A. 2003;100(14):8389-94. doi: 10.1073/pnas.1433000100.

\section{Figures}




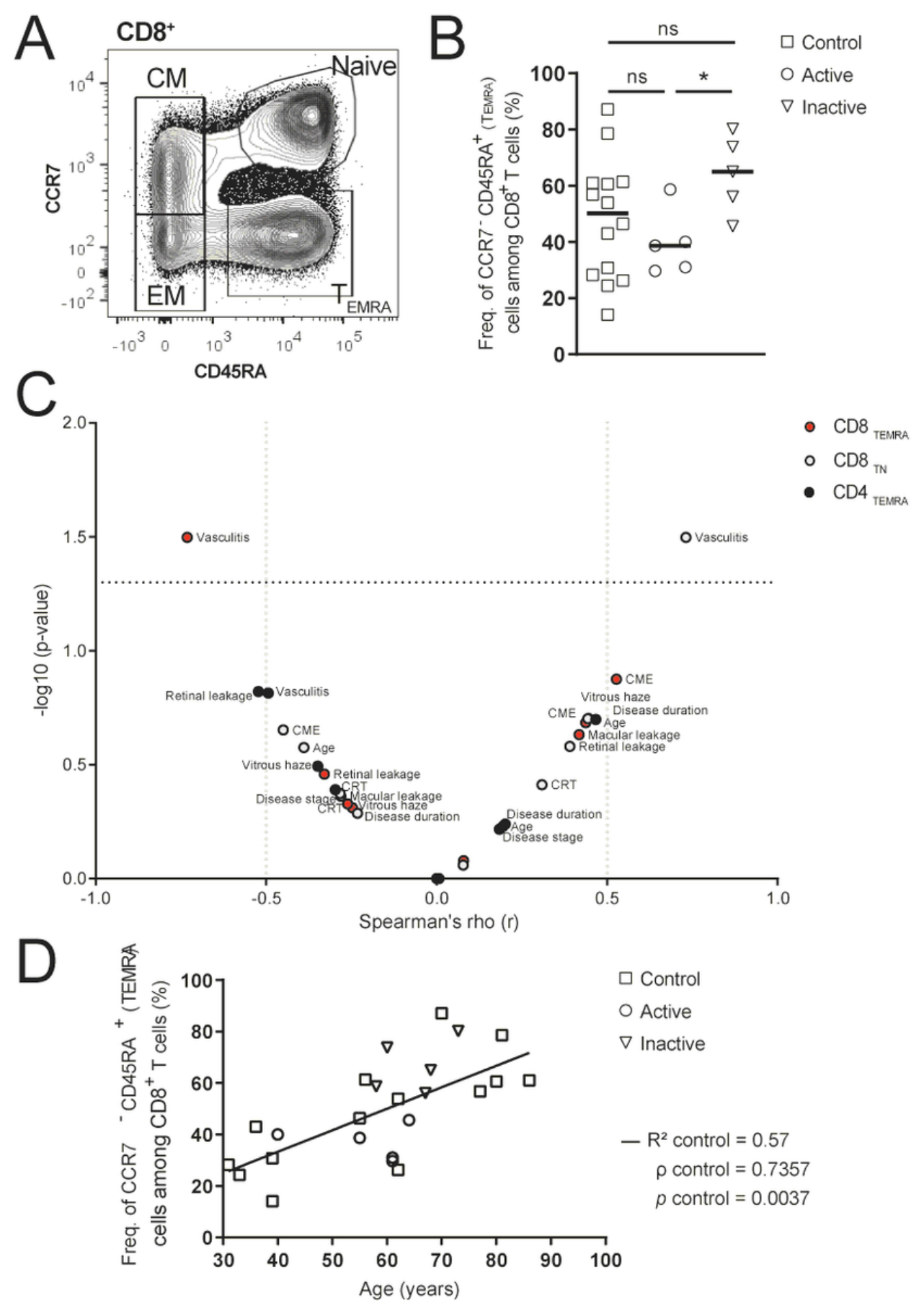

Figure 1

The activity state of BSRC affects peripheral CD8+ TEMRA cells. (A) Exemplary strategy of gating CD8+ T-cell stages: TCM (CCR7+CD45RA-), TEM (CCR7-CD45RA-), naïve (CCR7+CD45RA+), and TEMRA (CCR7-CD45RA+). (B) Blood analysis of peripheral CD8+ TEMRA cells from controls compared to disease-active and -inactive BSRC patients. Lines indicate the median. Statistical analysis was performed using Student's t-test with Welch's correction $\left(p<0.05^{\star}\right)$. (C) Volcanoplot (-log10) shows Spearman's $\rho$ correlation coefficient of immunological versus clinical parameters of significant altered CD4+ and CD8+ T-cell populations in BSRC patients. (D) Linear regression of CD8+ TEMRA cells with age of active and inactive BSRC patients and control probands. The population of CCD7-/CD45RA- was in one inactive patient absent, therefore the figures $1 \mathrm{~B}$ and $1 \mathrm{D}$ include $\mathrm{n}=5$ inactive patients. $\mathrm{BSRC}$, birdshot retinochoroiditis; $\mathrm{CM}$, central memory; CME, cystoid macula edema; CRT, central retinal thickness; EM, effector memory; Freq., frequency; NS, not significant; TEMRA, terminally differentiated effector memory CD45RA+ T cells; 
A
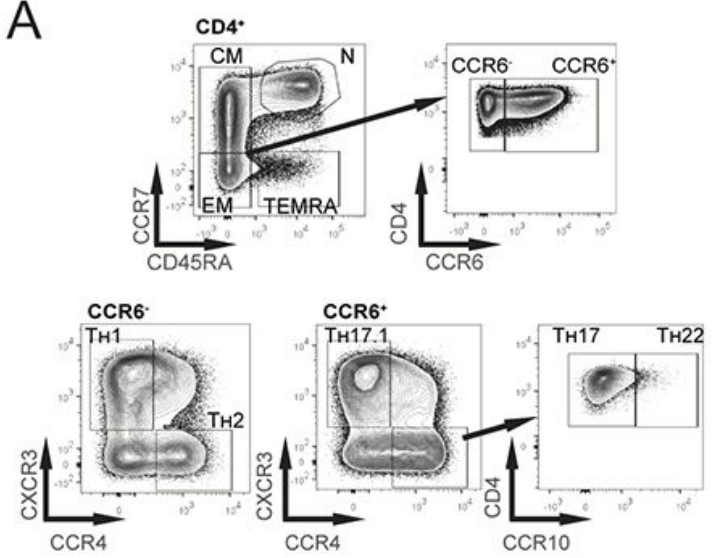

B
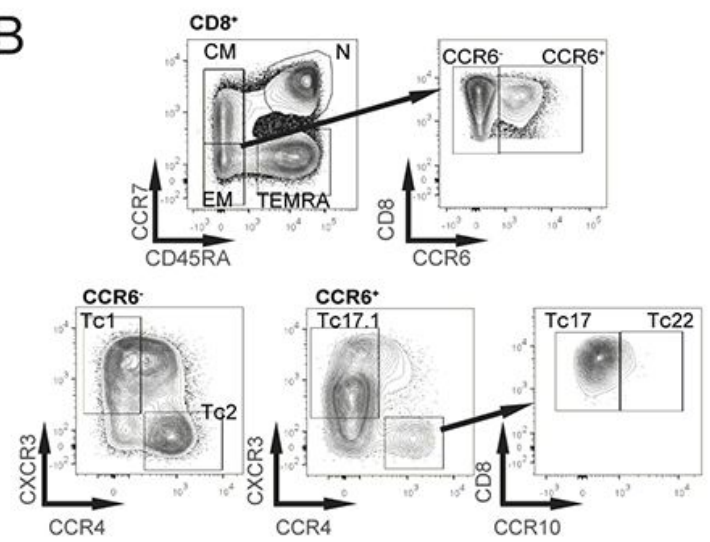

C
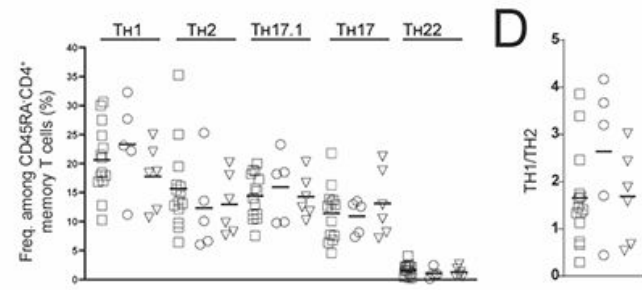

E

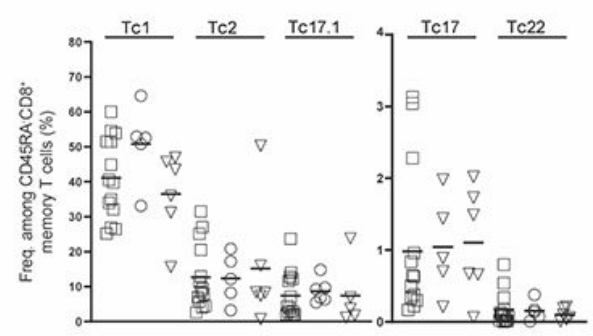

$\mathrm{F}$

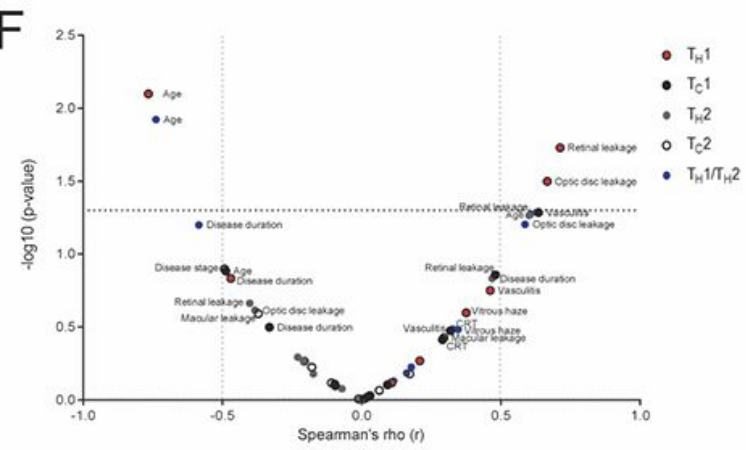

\section{Figure 2}

Inflammatory T-cell subsets in BSRC blood. (A) CD4+ and (B) CD8+ CD45RA-central and effector memory T cells were used to gate CCR6+ and CCR6- fractions. CCR6- cells were further distinguished in T1, based on CXCR3 expression or T2, based on CCR4 expression. CCR6+ cells were distinguished in T17.1, based on CXCR3 expression and T17 and T22 subsets were gated based on CCR4 and CCR10 expression. (C) Lines show median frequencies of CD4+ TH1, TH2, TH17.1, TH17 and TH22 T-cell subsets of controls and active/inactive BSRC patients. (D) The frequencies of $\mathrm{TH} 1$ and $\mathrm{TH} 2$ fractions were used to calculate a TH1/TH2 ratio. (E) Lines show median frequencies of CD8+ TC1, TC2, TC17.1, TC17 and TC22 T-cell subsets. (F) Volcanoplot (-log10) shows Spearman's $\rho$ correlation coefficient of immunological versus clinical parameters of $\mathrm{TH} 1, \mathrm{TH} 2, \mathrm{TC} 1, \mathrm{TC} 2 \mathrm{~T}$-cell populations and $\mathrm{TH} 1 / \mathrm{TH} 2$ ratio of BSRC patients. BSRC, birdshot retinochoroiditis; CM, central memory; CME, cystoid macula edema; CRT, central retinal thickness; EM, effector memory; N, naïve; TC, cytotoxic T cell; TH, T-helper; TEMRA, terminally differentiated effector memory CD45RA+; 

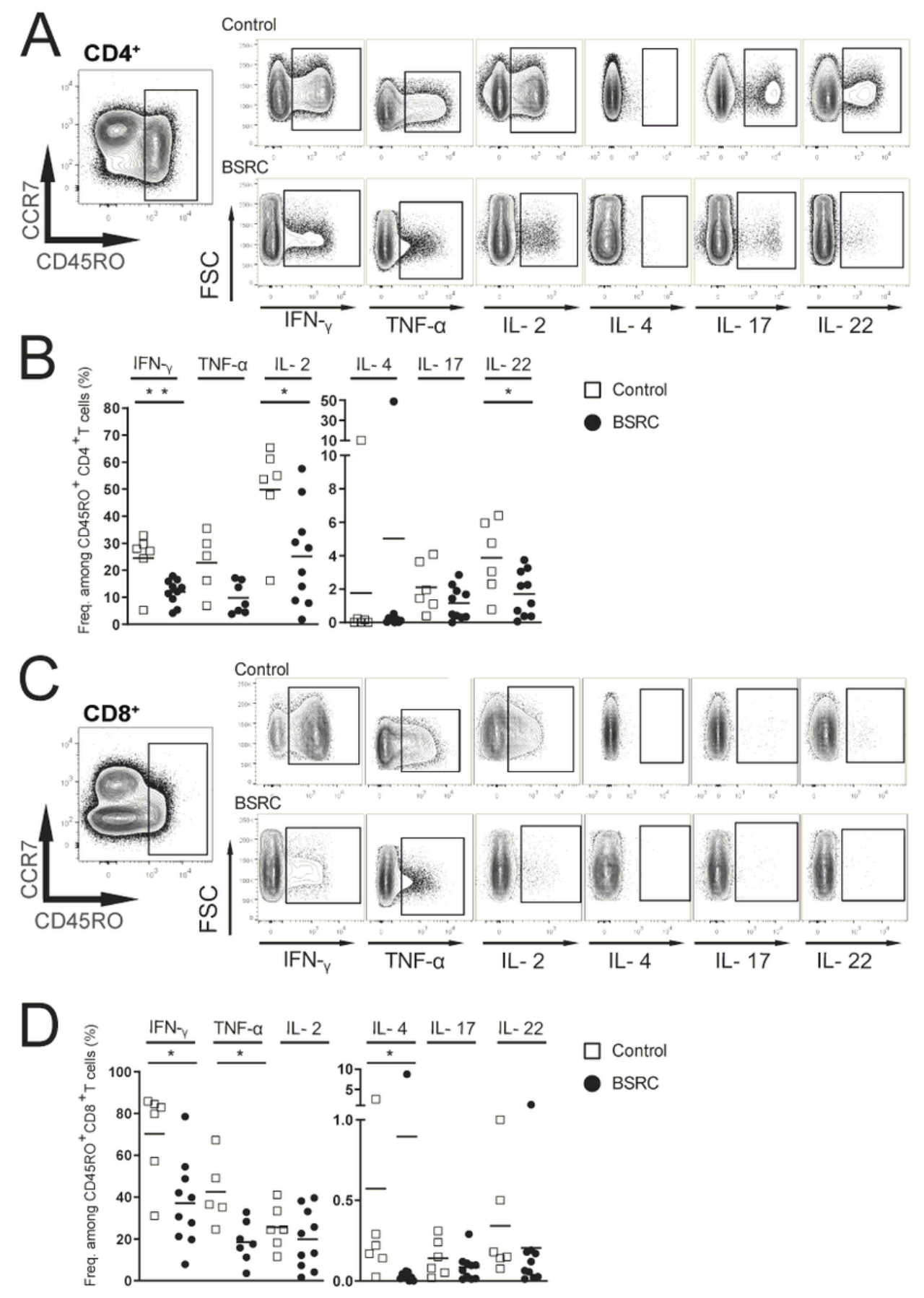

\section{Figure 3}

Reduced potential of BSRC memory T-cells to exert effector function. (A) Exemplary gating strategy of CD45RO+ memory T-cells and exemplary gating strategy of different cytokines after $6 \mathrm{~h}$ polyclonal activation in $C D 4+(A)$ and CD8+ (C) T cells in control probands (upper row) and patients (lower row) respectively. (B, D) Analysis of IFN- $\gamma$, TNF- $a$, IL-2, IL-4, IL-17, and IL-22-producing CD45RO+ T-cell fractions in controls and BSCR patients. Lines indicate median. Mann Whitney U test was used for statistical analysis $p<0.05^{\star}, p<0.05$. BSRC, birdshot retinochoroiditis; IFN-y, interferon gamma; IL, interleukin; TNF-a, tumor necrosis factor alpha; 